\title{
Living arrangements and socio-demographic conditions of older adults in Cambodia
}

Zachary Zimmer

Population Council

Sovan Kiry Kim

Follow this and additional works at: https://knowledgecommons.popcouncil.org/departments_sbsr-pgy

Part of the Demography, Population, and Ecology Commons, Family, Life Course, and Society

Commons, Gerontology Commons, and the International Public Health Commons

How does access to this work benefit you? Let us know!

\section{Recommended Citation}

Zimmer, Zachary and Sovan Kiry Kim. 2002. "Living arrangements and socio-demographic conditions of older adults in Cambodia," Policy Research Division Working Paper no. 157. New York: Population Council. Version of record: https://doi.org/10.1023/A:1014582603718 


\section{Living Arrangements and} Socio-D emographic Conditions of Older Adults in Cambodia

Zachary Zimmer Sovan Kiry Kim 


\section{Living Arrangements and Socio-Demographic Conditions of Older Adults in Cambodia}

Zachary Zimmer

Sovan Kiry Kim

Zachary Zimmer is Research Associate, Policy Research Division, Population Council. Sovan Kiry Kim is Lecturer, Sociology Department, Royal University of Phnom Penh, Phnom Penh, Cambodia. 


\begin{abstract}
Since the takeover of Cambodia by the Khmer Rouge in 1975, analysis of social conditions in the country has been lacking. Only recently has dependable socio-demographic data become available. We use some of these data to examine living arrangements and other socio-demographic conditions among Cambodia's older population and compare results to those recently found in Thailand and Vietnam. On balance, living arrangements in Cambodia are similar to those in neighboring countries. Older adults are likely to be living with a grown child and in a variety of arrangements involving different family members. To determine gender preference for coresident children we adjust living arrangement patterns for Cambodia's unique sex and marital status structure. We find a predominance of the elderly living with never-married children of either sex and a slight preference for living with daughters. Older adults in Cambodia may face particular challenges due to the influences of the past decades of instability and violence. We conclude with a discussion of how future research might assist in developing a national policy for older adults.
\end{abstract}

This material may not be reproduced without written permission from the authors. 
Cambodia's recent demographic history has been influenced by periods of civil war, massacres, famine, disease, mass out-migration, and occupation by neighboring states (Chandler 2000; Keirnan 1996). Living conditions were particularly harsh during Pol Pot's rule between 1975 and 1979, a time in which millions of excess deaths occurred (Meng-Try 1981). Estimates of the number who died during this period vary greatly. While even moderate guesses reach one million, it is within the realm of possibility that more than three million perished owing to violence, disease, and famine (Heuveline 1998; Vickery 1986). In addition, up to one million people left Cambodia between 1975 and 1985 to seek sanctuary beyond its borders (Gordon 1990).

During its period of instability Cambodia was virtually isolated from the outside world. One consequence was that little communication took place between researchers in Cambodia and their counterparts abroad (Huguet 1991). Moreover, for political and ideological reasons, the Khmer Rouge regime beginning in 1975 eliminated academic institutions and banned most forms of scholarly research (Chandler 2000; Keirnan 1996). In this period of isolation, no census was taken nor were reliable demographic data accumulated. Vietnam ceased its occupation of Cambodia in 1989 and UN-sponsored elections were held in 1993. Only since then has monitoring of social conditions resumed. The 1998 census represents the first taken since 1962 (Huguet et al. 2000). The 1990s saw several nationally based socioeconomic and demographic surveys conducted by Cambodia's National Institute of Statistics (1997a), and a Demographic and Health Survey has recently been completed. To date, only a handful of socio-demographic studies have incorporated these recent data to examine the living conditions of Cambodians and to assess how the population fared during the decades of violence and turmoil (notable examples include Beaufils 2000 and Huguet et al. 2000).

When it comes to its elderly population, Cambodia remains a "black box." This is unfortunate for a number of reasons. Cambodia lies near a number of countries in Southeast Asia where population aging has been receiving substantial attention (Hermalin 1995). Yet, there has been no such research that would allow Cambodia to be situated within the broader cultural context of the region. Cambodia's violent recent history has created a unique demographic milieu within which its older population lives, and, as such, older adults in Cambodia are faced with challenges distinct from those of its neigh- 
bors. For example, the excess mortality that Cambodia experienced during recent conflicts has influenced the availability of social support for its older population. Deterioration of vital infrastructure, such as roads and health facilities, impinges on the accessibility that older adults have to whatever health services are available. Cambodia is not in the group of countries that are currently "aging." However, given its geographic proximity to countries that have rapidly reduced their fertility and given that Buddhism, the predominant religion in Cambodia, embodies no inherent disapproval of contraception, fertility rates are projected to fall by 40 percent over the next two decades, and aging will eventually take place (National Institute of Statistics 2000).

Excluding Kato's (2000) review of data from a small purposively collected sample, we can find no other empirical investigations that examine even the most basic characteristics of older adults in Cambodia. The current study is primarily concerned with the living arrangements of older adults. But given the paucity of previous research, we begin by examining some of the related social and demographic conditions. With regard to living arrangements, we examine both the kinds of households in which older adults live and the predominant characteristics of coresident children. By drawing comparisons with neighboring countries, we place the elderly of Cambodia within a geographic and cultural context. The study employs data from a recent national survey that allows reliable discussion of the social and demographic circumstances of the elderly in Cambodia.

\section{Living Arrangements of Older Adults}

The household in developing societies is perhaps the most crucial social institution for its older members. At later ages individuals often experience reductions in physical functioning and tend to acquire health problems that make it difficult to conduct daily activities, work for pay, or perform other functions necessary for survival. Older adults, then, require various types of support, including financial, physical, and emotional. This may be more the case in countries like Cambodia where harsh conditions have prevailed for many years. Households also represent the institution responsible for the distribution of economic and other goods (Thornton, Chang, and Sun 1984), and they serve as the main venue through which age, gender, kinship, and economic roles are expressed. Exchanges that take place between elderly and younger members create dynamics for 
the survival and functioning of the family within a broader societal structure. "As such, they both reflect and contribute to the fundamental structure of the society as a whole" (Casterline et al. 1991: 2).

From a broad range of studies, we know that coresidence between older parents and at least one adult child is a central feature of the familial support system of developing countries in Asia and elsewhere (Asis et al. 1995; Bongaarts and Zimmer 2001; DaVanzo and Chan 1994; Hermalin, Ofstedal, and Chang 1996; Kim and Choe 1992; Knodel, Saengtienchai, and Ingersoll-Dayton 1999; Natividad and Cruz 1997). We also know that the sex and marital status of a coresident child have implications for social security and support (Anh et al. 1997; Ofstedal, Knodel, and Chayovan 1997). Mason (1992) identifies two predominant patterns in Asia. Families in South and East Asia tend to be organized around patrilineal systems, where males dominate ownership of resources and women, when they marry, take the identification of the husband's family. In these societies older adults tend to live with a married son and are most likely cared for, when care is needed, by a daughter-in-law. Much of Southeast Asia, meanwhile, is organized around bilateral systems, where women and men are considered equal members of their natal families and usually no preference is expressed concerning the gender of the coresident child. In some instances, such as in Thailand, the preference is for living with the youngest daughter, who is the least likely to be married (Knodel, Chayovan, and Siriboon 1992).

In the current study, we draw comparisons with recent research conducted in two of Cambodia's neighboring countries, Thailand and Vietnam. There tends to be a slight preference for living with daughters in Thailand (Knodel and Debavalya 1997), while Vietnam is characterized by son preference (Anh et al. 1997). In the south, the area of Vietnam that directly borders Cambodia, a slight son preference is seen but not to the extent found in the north. Anh et al. (1997) speculate that these variations are due to the geographic proximity of southern and northern Vietnam with other parts of Asia where the respective family systems are found.

Although no empirical studies directly measure the living arrangements of older Cambodians and their preference for living with male or female children, we might speculate on these on the basis of what we know about Cambodian culture and values. Like Thailand, Cambodia is primarily a Buddhist country and Buddhism does not ap- 
pear to embody the patrilineal values of inheritance typical in many Asian societies (Mason 1992). On the contrary, Kato (2000) notes that older adults in Cambodia tend to rely upon a daughter, typically the youngest daughter, for support. When couples marry, they do not appear to follow a cultural preference regarding whether to take up residence with the parents of the husband or the wife. Furthermore, the youngest daughter is likely to inherit the largest portion of family property after the death of the parents. This bilateral, and perhaps even slightly matrilineal, value system would likely place Cambodia within the category of living arrangements found in Thailand.

\section{DATA}

Our data come from the 1997 Socio-Economic Survey of Cambodia, a project co-sponsored by the United Nations Development Programme and the Swedish International Development Cooperation Agency, under the auspices of the World Bank. The National Institute of Statistics in Cambodia implemented the survey. These data are among the first available on specific socio-demographic conditions and characteristics of the population with broad coverage. The primary objective of the survey was to provide information for planning and monitoring of the population and to provide a baseline for national account estimation (National Institute of Statistics 1997a, 1997b).

The survey employed two-stage stratified probability sampling, with villages as the primary sampling unit and households as the secondary units. In total, 486 villages were chosen from 18 provinces and two self-governing municipalities (Phnom Penh and Sihanoukville). Two provinces, Preah Vihear and Otchar Mean Chey, were excluded owing to dangers associated with land mines and rebel forces that existed at the time of the survey. Weights were assigned to each village so that the total sample, when weighted, was representative of the total population. We normalized sample weights so the sample size for our analysis would equal the number of collected observations. In all, information on 29,931 individuals in 6,010 households was obtained. The current study concentrates on the population aged 60 and older, which we define here as the elderly. There were 1,815 individuals 60 and older, representing about 6 percent of the sample population. In addition, 1,415 households (or 24 percent) contained at least one older adult.

The data structure involves separate records for each individual in a household. Records include information on age, sex, marital status, and relationship to the house- 
hold head. Because the data were not collected with specific reference to older adults, information on living arrangements of the elderly had to be reconstructed by determining the association between each individual in the household and the older adult. If an older adult is the household head or the spouse of the household head, the reconstruction is straightforward. In addition, if the older adult is a parent or parent-in-law of the household head, relationships to other members are straightforward. In cases where the older adult is a more distant relation to the household head, say an uncle, the relationship between the older adult and other household members is more difficult to determine. For the current analysis, all household members were coded as being a spouse, son, daughter, son-in-law, daughter-in-law, grandchild, or other relation of the older adult. In 40 of the 7,046 relationships, or 0.6 percent, we could not assess with confidence the relationship between the older adult and the household member. These cases were coded with the category "other." Because they are a small number and we are mostly interested in the relationships that are easier to determine (e.g., spouse or child), this coding does not hamper our analyses.

Although data collection of this nature provides us with the characteristics of the older adult, several pieces of information are missing. For instance, we do not know how many living children an older adult has; we know only how many an elderly individual is currently living with. If older adults are not living with a child, we do not know the proximity of other living children. Although we can reconstruct whether older adults are living with married or unmarried sons or daughters, we do not know the birth order of all children and therefore we cannot determine whether they tend to live with older or younger children. For other potentially important characteristics, such as education, we have information for older adults and their coresident children, but we know nothing about non-coresident children, and therefore cannot assess the effects of such factors as education on living circumstances. We also lack information on exchanges that take place within the household, such as assistance older adults may receive from their children. These limitations on our investigation compel us to concentrate on descriptive analyses of current situations. But we can make several useful inferences from our data. For instance, although we cannot directly assess living arrangement preferences, combining the observed living arrangement patterns with overall population characteristics leads to some implications that we discuss below. 


\section{Older CAMbodian Adults in Socio-Demographic CONTEXT}

A map of Cambodia is provided in Figure 1. Geographically, the country is centrally located in Southeast Asia. It is made up of 24 administrative units, including 20 provinces and four self-governing municipalities. Two major waterways, the Mekong River and the Tonle Sap, are central to life in Cambodia (Colet and Eliot 1997). Given that roads and railways are underdeveloped, the waterways provide a way of moving about the country, and the fishing that their waters permit represents an important economic activity for many Cambodians. The rivers are navigable by cargo ship directly into the capital of Phnom Penh, so they are also important for trade. The 1998 census estimated the population of Cambodia at about 11.4 million (Huguet et al. 2000; National Institute of Statistics 2000). The crude birth rate projected for 2001 is about 34 and the projected death rate slightly below 10 (both expressed per 1,000 population), which if correct means that Cambodia's population is growing at a rate of about 2.4 percent per annum. Fertility is higher and life expectancy is lower than in many Southeast Asian neighbors. The total fertility rate in Cambodia is estimated to be a little more than five children per woman, while life expectancy at birth is estimated at about 56 years (National Institute of Statistics 2000). By comparison, the United Nations estimates fertility to be 1.7 in Thailand and 2.2 in Vietnam, while life expectancy in these two neighboring countries is estimated to be 73 and 72 years (United Nations 1999). Hence, mortality and fertility in Cambodia might be described as being in an early stage of transition.

Table 1 presents basic social and demographic characteristics of Cambodians by age group and compares these to the total population. The top part of the table looks at individual characteristics. Asterisks indicate that the percent value reported for a particular age group is significantly different from the percent reported for the total population (based on a t-value that tests differences in proportions; Blalock 1979). As the table indicates, Cambodia is largely an agrarian country with about 80 percent of the population living in rural areas. There is little difference in the percent living in rural areas across age groups. 
Figure 1 Map of Cambodia and selected urban centers

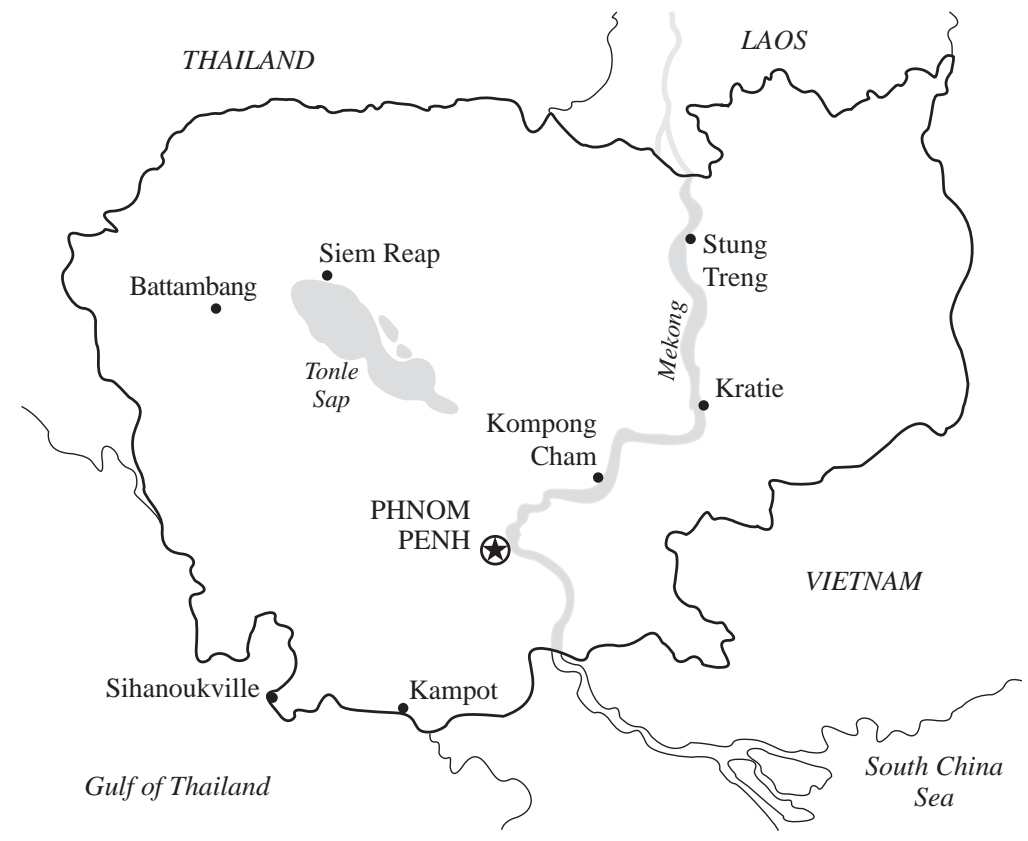

Source: World Factbook 1998.

We divide the country into five regions based on the "natural regions" definition of Cambodia used by the National Institute of Statistics (2000). The Plains region consists of provinces bordering Vietnam to the south and lying east of the Mekong River. The Tonle Sap region lies to the northwest, bordering the Tonle Sap lake and/or Thailand. The Coastal region contains a few provinces bordering the Gulf of Thailand to the southwest. The Mountain region consists of several sparsely populated provinces bordering Laos and Vietnam to the north and east. We consider Phnom Penh as a separate region. In a socioeconomic sense, the first four regions share many similarities. A large majority of the working populations in these regions are employed in agriculture, and most individuals live in rural areas. In comparison to many other Asian countries, levels of poverty are high in Cambodia and literacy is low; again, these levels are fairly consis- 
Table 1 Selected individual and household characteristics of the Cambodian population: Total and by age group

\begin{tabular}{|c|c|c|c|c|}
\hline $\begin{array}{l}\text { Individual } \\
\text { characteristics }\end{array}$ & $\begin{array}{c}\text { Total } \\
\text { population }\end{array}$ & $\begin{array}{l}\text { Population } \\
18 \text { to } 59\end{array}$ & $\begin{array}{l}\text { Population } \\
60 \text { and older }\end{array}$ & $\begin{array}{r}\text { Population } \\
70 \text { and older }\end{array}$ \\
\hline \multicolumn{5}{|l|}{ Rural/urban residence $(\%)$} \\
\hline Rural & 79.4 & 78.6 & 80.3 & 80.8 \\
\hline Urban & 20.6 & 21.4 & 19.7 & 19.2 \\
\hline \multicolumn{5}{|l|}{ Region $(\%)$} \\
\hline Plains & 52.3 & 52.2 & $57.4^{*}$ & $59.7 *$ \\
\hline Tonle Sap & 26.6 & 26.2 & 23.8 & 22.4 \\
\hline Coastal & 6.6 & 6.3 & 5.4 & 5.5 \\
\hline Mountain & 4.5 & 4.5 & 3.7 & 3.1 \\
\hline Phnom Penh & 9.9 & 10.8 & 9.6 & 9.3 \\
\hline \multicolumn{5}{|l|}{ Sex and marital distribution (\%) } \\
\hline Female & 52.4 & $55.2 *$ & $57.2 *$ & $58.8^{*}$ \\
\hline Married & 35.1 & $68.1 *$ & $57.7 *$ & $46.2 *$ \\
\hline \multicolumn{5}{|l|}{ Education $(\%)$} \\
\hline Any formal schooling & 65.8 & $70.2 *$ & $27.3 *$ & $21.3^{*}$ \\
\hline Literate & 59.8 & $69.5^{*}$ & $28.8 *$ & $23.1 *$ \\
\hline \multicolumn{5}{|l|}{ Health $(\%)$} \\
\hline Reporting an illness in last 4 weeks & 14.0 & 14.4 & $27.8 *$ & $29.4 *$ \\
\hline Reporting a disability & 2.2 & 2.9 & $5.6^{*}$ & $8.3^{*}$ \\
\hline $\begin{array}{l}\text { Household } \\
\text { characteristics }\end{array}$ & $\begin{array}{c}\text { All } \\
\text { households }\end{array}$ & $\begin{array}{c}\text { With } \\
\text { someone } \\
60 \text { and older } \\
\text { present }\end{array}$ & $\begin{array}{c}\text { With } \\
\text { someone } \\
70 \text { and older } \\
\text { present }\end{array}$ & $\begin{array}{c}\text { With } \\
\text { someone } \\
60 \text { and older } \\
\text { as head } \\
\end{array}$ \\
\hline \multicolumn{5}{|l|}{ Ethnicity of household head (\%) } \\
\hline Khmer & 95.5 & 95.0 & 94.8 & 95.1 \\
\hline Cham & 3.4 & 3.5 & 3.5 & 3.5 \\
\hline Chinese & 0.2 & 0.5 & 0.6 & 0.4 \\
\hline Vietnamese & 0.4 & 0.5 & 0.4 & 0.6 \\
\hline Other & 0.5 & 0.5 & 0.7 & 0.4 \\
\hline \multicolumn{5}{|l|}{ Housing quality (\%) } \\
\hline Most basic & 73.1 & 71.9 & 74.9 & 74.6 \\
\hline Almost basic & 12.9 & 13.6 & 10.8 & 12.9 \\
\hline Intermediate & 5.7 & 5.2 & 5.2 & 4.8 \\
\hline Almost modern & 4.1 & 4.5 & 4.5 & 3.7 \\
\hline Modern & 4.2 & 4.6 & 4.6 & 4.1 \\
\hline $\begin{array}{l}\text { Households owning a car, truck, } \\
\text { motorcycle, or scooter }(\%)\end{array}$ & 21.4 & 19.4 & 18.5 & 15.9 \\
\hline $\begin{array}{l}\text { Households with agriculture or } \\
\text { fishing as main source of income (\%) }\end{array}$ & 68.9 & 68.1 & 66.9 & 67.6 \\
\hline
\end{tabular}


tent across the four regions outside Phnom Penh. Phnom Penh differs in that it is wholly urban, with only 10 percent of residents being employed in agriculture. The poverty rate for Phnom Penh is about one-third the rate for the rest of the country, and the literacy rate is 85 percent, a figure much above the other regions. The fertile Plains region contains about half of the Cambodian population.

Compared with other age groups in Cambodia, the elderly are significantly less educated; only about 27 percent of those aged 60 and older report having any schooling, while only 29 percent report being able to read. Proportions are even less for those 70 and older. The elderly are also significantly less likely to be healthy. About twice as many reported an illness during the four weeks preceding the survey compared with younger groups. Those 70 and older are about four times as likely as the total population to report a disability. For the purpose of this survey, disabilities were defined as amputations, being blind, deaf, mute, mentally disturbed, permanently disfigured, or paralyzed. The disability item for the current survey was likely constructed with the aim of determining the prevalence of severe disabilities caused by the past years of war; hence, for an elderly population, it is clearly a narrow definition and does not embrace the types of activities of daily living or basic upper and lower body movements that have become common in gerontological studies (Katz et al. 1963; Nagi 1976). As a result, these disability figures underestimate physical limitations as typically defined, and the figures are used here for descriptive purposes and as a factor that might relate to living arrangements of the elderly.

The bottom part of Table 1 provides household characteristics. We present data for all households, households with someone 60 and older present, households with someone 70 and older present, and households with an elderly person as the household head. Here we see very little difference across ages. Ninety-five percent of Cambodian households report the head as Khmer with a few others being Muslim-Cham, Chinese, or Vietnamese. These data concur with those of Robinson (1989). We cannot determine income levels from the data used here; we do, however, have proxy measures of economic status. Housing type is a measure that categorizes the quality of housing in which people live. Modern houses contain something other than an earth or unpolished wood floor, as well as electricity, piped water, and a sewer or septic tank for a toilet. Houses 
characterized as almost modern have three of these qualities, intermediate homes have two, almost basic have one, and the most basic homes have none of these modern features. A majority of houses in Cambodia can be classified as being most basic. Households headed by an elderly person are slightly less likely to possess a car, truck, or motorcycle, but the difference is not statistically significant. Finally, the main source of income for more than two-thirds of Cambodian households is an agricultural endeavor.

The years of war, famine, and disease that plagued Cambodia for much of its recent history have created a unique age and sex structure that in turn has implications for the elderly population. The population age pyramid for Cambodia presented in Figure 2 is derived from data in the 1997 Socio-Economic Survey. The bars on either side of the centerline indicate the proportion of males and females within the total population for five-year age brackets (each vertical line represents one percentage point), with the elderly being grouped into a single bracket (60+) at the top of the pyramid. The period of turmoil in Cambodia resulted in higher male than female deaths, a fact that is apparent from the deficiency in the proportion of males beginning around age 20. A relative shortage of males is particularly noticeable in the age groups between 35 and 54 . These individuals would have been aged 10 to 30 at the start of the Khmer Rouge rule of Cambodia in 1975. In short, Cambodia has a female-predominant population in particular age groups. We also notice a small proportion in the age group 20 to 24 relative to those in the next older or younger group. This is the result of drastically reduced fertility in the late 1970s during a period of major disruption of social life. The age/sex structure reported here is in concurrence with Huguet et al.'s (2000) analysis of the 1998 Cambodian census.

Table 2 shows age and sex distributions in ten-year age groups for the total population and for those aged 60 and older. About 6 percent of the total Cambodian population is 60 years of age and older, although the fraction is somewhat higher for women than for men (6.6 percent versus 5.5 percent). More than 50 percent of the population is 19 and younger. This large youth bulge is the result of excess mortality in middle-aged groups and of high fertility rates in the 1980s, which recovered quickly after the height of social unrest (Robinson 1989). This has created a high dependency 
Figure 2 Population age pyramid of Cambodia, 1997

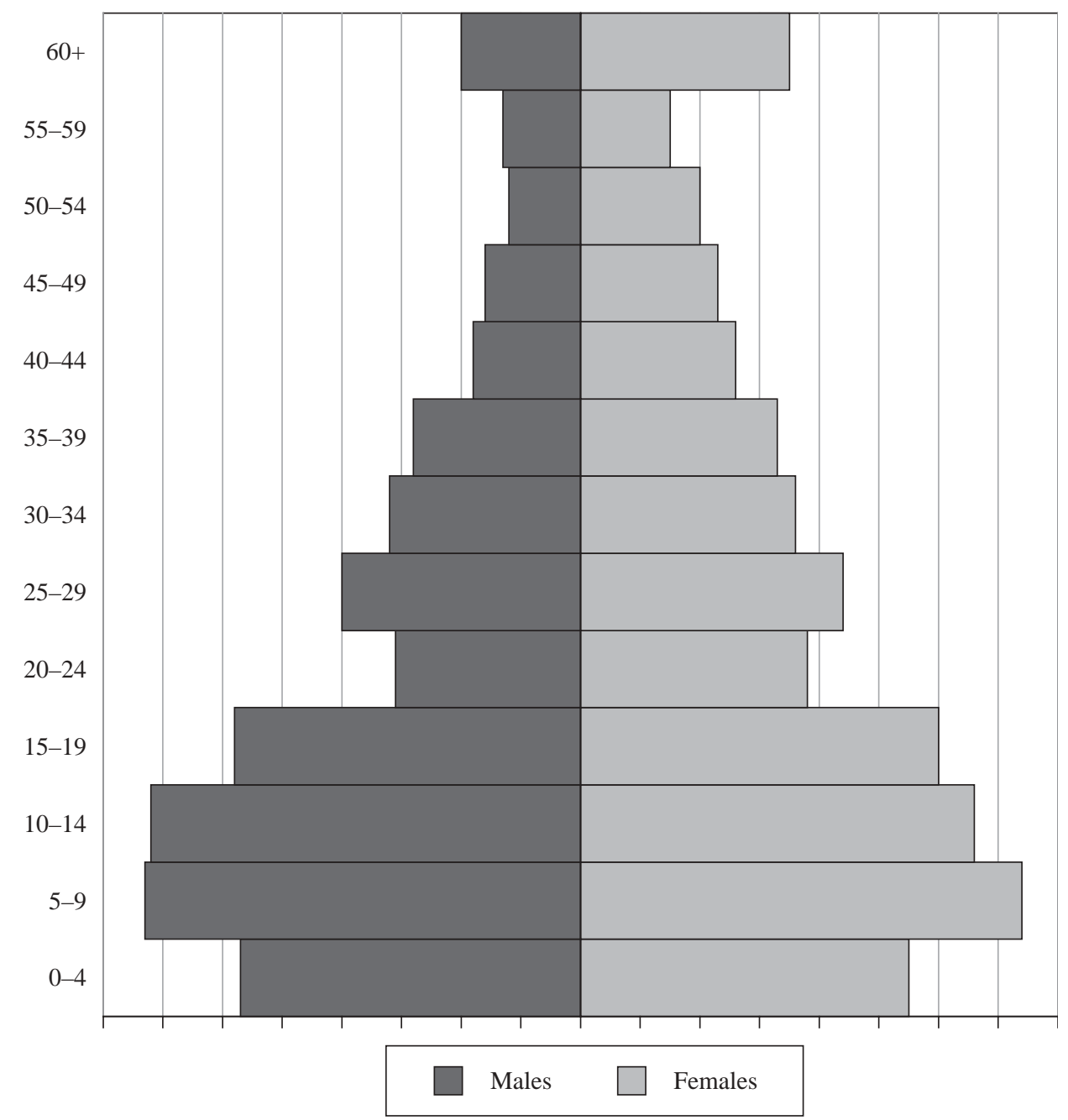

Note: Each tick represents 1 percent of the population of Cambodia, or about 114,000 persons.

ratio in Cambodia (that is, the number of young and old as a proportion of the number in working ages). Almost one-third of the population is either over 60 or under 10 years of age. 
Table 2 Age and sex distribution and sex ratio of the Cambodian population: Total and those aged 60 and older

\begin{tabular}{lcccc}
\hline & $\begin{array}{c}\text { \% of total } \\
\text { population }\end{array}$ & $\begin{array}{c}\text { \% of } \\
\text { all males }\end{array}$ & $\begin{array}{c}\text { \% of } \\
\text { all females }\end{array}$ & Sex ratio $^{\mathbf{a}}$ \\
\hline Of the total population & & & & \\
0 to 9 years old & 25.9 & 27.4 & 24.5 & 101 \\
10 to 19 & 25.7 & 27.4 & 24.1 & 103 \\
20 to 29 & 15.2 & 14.8 & 15.6 & 86 \\
30 to 39 & 12.9 & 12.7 & 13.1 & 87 \\
40 to 49 & 8.3 & 7.2 & 9.3 & 70 \\
50 to 59 & 6.0 & 5.1 & 6.7 & 69 \\
60 and older & 6.1 & 5.5 & 6.6 & 75 \\
Total & 100.0 & 100.0 & 100.0 & 91 \\
Of those 60 and older & & & & \\
60 to 69 years old & 64.2 & 65.5 & 63.2 & 76 \\
70 to 79 & 29.1 & 28.1 & 29.8 & 71 \\
80 and older & 6.7 & 6.3 & 7.0 & 67 \\
Total & 100.0 & 100.0 & 100.0 & 75 \\
\hline
\end{tabular}

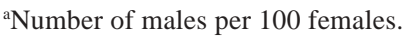

Table 2 also indicates the number of males per 100 females within age groups. These sex ratios are unusually low in Cambodia for all age groups after 20. This can be attributed to higher male mortality during periods of social disruption, famine, and violence. For instance, between ages 40 and 49 there are only about 70 men per 100 women. These ratios concur with other recent estimates (Huguet et al. 2000; United Nations 1999).

Examining differences in marital status of men and women in different age groups further emphasizes the point. The top part of Table 3 shows differences in marital status distributions between men and women in broad age categories. While less than 2 percent of men aged 18 to 59 are widowed, the figure for women is 14 percent. Twenty-two percent of women 40 to 49 and 39 percent of women 50 to 59 are widowed. This compares to some 2 percent and 5 percent of men respectively. Hence, women in these age groups are eight to ten times more likely than men to be widowed. Widowhood is also more frequent among elderly women. Over 50 percent of women aged 60 to 69 are widowed, and the proportion increases to nearly 90 percent for those 80 and older. For men, the proportion widowed does not reach 40 percent even among the oldest-old. 
Table 3 Marital status distribution of the Cambodian population: Total and by age group

\begin{tabular}{lcllll}
\hline & Single & Married & Widowed & Other & Total \\
\hline By broad age group & & & & & \\
Men 18 to 59 & $24.0 \%$ & $73.8 \%$ & $1.7 \%$ & $0.5 \%$ & $100.0 \%$ \\
Women 18 to 59 & 20.4 & 63.6 & 14.1 & 2.0 & 100.0 \\
Men 60 and older & 0.5 & 80.8 & 18.5 & 0.1 & 100.0 \\
Women 60 and older & 1.4 & 38.8 & 59.6 & 0.2 & 100.0 \\
& & & & & \\
By specific age group & & & & & \\
Men: Nonelderly & $52.4 \%$ & $46.4 \%$ & $0.9 \%$ & $0.3 \%$ & $100.0 \%$ \\
18 to 29 & 4.8 & 93.1 & 1.3 & 0.8 & 100.0 \\
30 to 39 & 1.1 & 96.1 & 2.3 & 0.6 & 100.0 \\
40 to 49 & 0.3 & 94.4 & 4.8 & 0.5 & 100.0 \\
50 to 59 & & & & & \\
Men: Elderly & $0.6 \%$ & $86.6 \%$ & $12.8 \%$ & $0.0 \%$ & $100.0 \%$ \\
60 to 69 & 0.5 & 72.1 & 26.9 & 0.5 & 100.0 \\
70 to 79 & 0.0 & 61.2 & 38.0 & 0.0 & 100.0 \\
80 and older & & & & & \\
Women: Nonelderly & $41.5 \%$ & $52.8 \%$ & $4.0 \%$ & $1.7 \%$ & $100.0 \%$ \\
18 to 29 & 9.4 & 77.6 & 10.4 & 2.6 & 100.0 \\
30 to 39 & 5.2 & 70.3 & 22.0 & 2.5 & 100.0 \\
40 to 49 & 1.4 & 58.2 & 39.4 & 0.9 & 100.0 \\
50 to 59 & & & & & \\
Women: Elderly & $1.8 \%$ & $46.4 \%$ & $51.5 \%$ & $0.3 \%$ & $100.0 \%$ \\
60 to 69 & 0.6 & 29.1 & 70.2 & 0.0 & 100.0 \\
70 to 79 & 1.4 & 11.1 & 87.5 & 0.0 & 100.0 \\
80 and older & & & & &
\end{tabular}

\section{LiVing ARRANGEMENTS OF OLdER CAMbOdians}

Table 4 examines the living arrangements of the elderly in Cambodia. To place Cambodia in a regional context, we include results from recent surveys conducted in neighboring Thailand and southern and northern Vietnam. On balance, the living arrangements of the elderly in Cambodia resemble those of its neighbors in that about 80 percent coreside with children. This is the case in nearly all Asian societies (Asis et al. 1995), but the situation in Cambodia closely resembles that of southern Vietnam, the part of Vietnam that directly borders Cambodia. Conversely, Cambodia's elderly are less likely than are Thais or Vietnamese to be living alone but more likely to be living with children only or with a spouse and at least one child. 
Table 4 Living arrangements of the Cambodian population aged 60 and older and comparisons with neighboring regions (in percent)

\begin{tabular}{|c|c|c|c|c|}
\hline Living arrangement & Cambodia & Thailand $^{\mathrm{a}}$ & $\begin{array}{l}\text { Southern } \\
\text { Vietnam }^{\text {b }}\end{array}$ & $\begin{array}{l}\text { Northern } \\
\text { Vietnam }^{\text {b }}\end{array}$ \\
\hline Living alone & 2.8 & 3.6 & 4.8 & 6.9 \\
\hline Spouse only & 7.3 & 11.6 & 4.5 & 12.5 \\
\hline Child(ren) only & 8.1 & 5.2 & 6.9 & 4.1 \\
\hline Others only & 4.9 & 5.7 & 5.8 & 3.5 \\
\hline Spouse and child(ren) & 21.0 & 15.0 & 16.3 & 14.4 \\
\hline Spouse and others & 4.3 & 6.3 & 3.0 & 3.4 \\
\hline Child(ren) and others & 30.1 & 23.4 & 28.7 & 26.4 \\
\hline Spouse, child(ren), and others & 21.3 & 29.2 & 30.0 & 28.7 \\
\hline $\begin{array}{l}\text { Spouse, with or without child(ren) } \\
\text { or others }\end{array}$ & 53.9 & 62.1 & 53.8 & 59.0 \\
\hline $\begin{array}{l}\text { Child(ren), with or without spouse } \\
\text { or others }\end{array}$ & 80.5 & 72.8 & 81.9 & 73.6 \\
\hline $\begin{array}{l}\text { Others, with or without spouse or } \\
\text { child(ren) }\end{array}$ & 60.6 & 64.6 & 67.5 & 62.0 \\
\hline Nucleated household $^{c}$ & 36.4 & 31.8 & 27.7 & 31.0 \\
\hline Three-generation family & 45.1 & 47.0 & 51.0 & 57.4 \\
\hline
\end{tabular}

${ }^{a}$ From Knodel, Amornsirisomboon, and Khiewyoo (1997: Table 3)

${ }^{\mathrm{b}}$ From Anh, Caong, Goodkind, and Knodel (1997: Table 2). Northern includes Hanoi and Red River Delta; southern includes Ho Chi Minh City and surrounding area.

${ }^{\mathrm{c}}$ Nucleated families include living with spouse, with children, or with spouse and children, but with no others.

The oldest members within any population have lived long enough to be in a resident situation with both a child and grandchildren. While over 21 percent of both Vietnamese and Thai elderly are 75 years of age and older, the same is true of less than 17 percent of Cambodia's elderly (United Nations 1999). Consequently, elderly Cambodians are less likely than their counterparts in Thailand and Vietnam to live in threegeneration households.

Only about 7 percent of Cambodian households consist of only an older adult and his or her spouse, while over 60 percent consist of an older adult and someone other than a spouse or a child even if a spouse or child is also present. This might include living with a grandchild or a child-in-law. Overall, a little more than one-third live in what can be called a nucleated household, that is, living with a spouse, child(ren,) or both spouse and child(ren). This fraction is comparable to, but nonetheless higher than in Thailand 
and Vietnam. In short, although the elderly in Cambodia appear to be living in a variety of household types with different arrangements and various family members, much like the elderly in neighboring countries, small nucleated households are less frequent than more multifarious arrangements.

A summary of living arrangement indicators for Cambodia's elderly population aged 60 and older is presented in Table 5. Here we also examine whether these indicators differ across a range of socio-demographic characteristics. Besides living alone, with a spouse, with children, and in three-generation families, we examine the percent living in a complex arrangement (living with someone who is not an immediate family relation) and average household sizes.

The table suggests some significant rural versus urban variations in living arrangements. Most notably, those living in urban areas are more likely to be living with children, in three-generation families, and in larger households. Regional differences are significant with respect to a couple of summary indicators, with residents of Phnom Penh most likely to be living in three-generation families and in larger households. These circumstances may be the result of a need to share housing costs in areas where they are high. Nevertheless, given the previously cited fact that Phnom Penh differs from the other four regions with respect to socioeconomic characteristics, it may be the similarities in living arrangement patterns, rather than the differences, that are most striking.

Associations between marital status, age, or sex, and living arrangements tend to reflect specific life-course circumstances. For example, the unmarried elderly are more likely to be living alone, clearly because no spouse is available. These individuals are also more likely to be living with children, in complex arrangements, or in three-generation families. Older age is also associated with a higher tendency to live in three-generation families. These associations may point to the higher probability of those at older ages experiencing both the death of a spouse and the birth of grandchildren. It may also be that when a spouse dies, older adults tend to move in with their children and others who can provide them with necessary support. Of course, our data, being cross-sectional in nature, cannot sort out which of these explanations is most pertinent. Higherquality housing is associated with greater likelihood of living in larger households and living with spouses, children, and grandchildren. This likely implies that larger house- 
Table 5 Summary living arrangement indicators of the Cambodian population aged 60 and older by selected socio-demographic characteristics

\begin{tabular}{|c|c|c|c|c|c|c|}
\hline & $\begin{array}{c}\% \\
\text { living } \\
\text { alone }\end{array}$ & $\begin{array}{l}\% \text { with } \\
\text { spouse }\end{array}$ & $\begin{array}{c}\% \text { with } \\
\text { children }\end{array}$ & $\begin{array}{c}\% \text { in three- } \\
\text { generation } \\
\text { family }\end{array}$ & $\begin{array}{c}\text { \%in } \\
\text { complex } \\
\text { arrangement }^{\mathrm{a}}\end{array}$ & $\begin{array}{c}\text { Mean } \\
\text { household } \\
\text { size } \\
\end{array}$ \\
\hline Total & 2.8 & 53.9 & 80.5 & 45.1 & 7.6 & 4.8 \\
\hline \multicolumn{7}{|l|}{ Residence } \\
\hline Rural & 3.0 & 55.5 & 79.5 & 42.7 & 7.3 & 4.7 \\
\hline Urban & 2.0 & 48.2 & 85.2 & 55.2 & 9.0 & 5.3 \\
\hline $\mathrm{P}$ & .28 & .01 & .02 & .00 & .28 & .00 \\
\hline \multicolumn{7}{|l|}{ Region } \\
\hline Plains & 3.0 & 55.8 & 79.0 & 42.4 & 7.1 & 4.7 \\
\hline Tonle Sap & 3.5 & 53.8 & 80.1 & 43.3 & 8.8 & 4.6 \\
\hline Coastal & 1.0 & 44.9 & 85.7 & 54.1 & 8.2 & 4.7 \\
\hline Mountain & 0.0 & 59.1 & 86.4 & 51.5 & 3.0 & 4.9 \\
\hline Phnom Penh & 2.3 & 47.4 & 86.3 & 58.3 & 8.0 & 5.4 \\
\hline $\mathrm{P}$ & .40 & .08 & .08 & .00 & .50 & .00 \\
\hline \multicolumn{7}{|l|}{ Marital status } \\
\hline Married & 0.3 & 93.8 & 78.7 & 34.0 & 5.4 & 4.8 \\
\hline Not married & 6.3 & 0.0 & 83.2 & 60.2 & 10.7 & 4.7 \\
\hline $\mathrm{P}$ & .00 & .00 & .02 & .00 & .00 & .40 \\
\hline \multicolumn{7}{|l|}{ Age } \\
\hline 60 to 69 & 3.4 & 60.9 & 81.0 & 36.5 & 6.8 & 4.6 \\
\hline $70+$ & 1.9 & 41.8 & 79.9 & 60.6 & 9.0 & 5.1 \\
\hline $\mathrm{P}$ & .06 & .00 & .59 & .00 & .10 & .00 \\
\hline \multicolumn{7}{|l|}{ Sex } \\
\hline Male & 1.2 & 79.4 & 81.2 & 34.4 & 7.4 & 4.9 \\
\hline Female & 4.2 & 35.1 & 80.2 & 53.2 & 7.7 & 4.7 \\
\hline $\mathrm{P}$ & .00 & .00 & .61 & .00 & .77 & .04 \\
\hline \multicolumn{7}{|l|}{ Housing quality } \\
\hline Most basic & 3.3 & 78.2 & 54.7 & 41.9 & 6.6 & 4.6 \\
\hline Almost basic & 1.6 & 84.3 & 56.5 & 45.8 & 8.9 & 5.0 \\
\hline Intermediate & 3.6 & 83.3 & 34.5 & 60.7 & 10.7 & 5.2 \\
\hline Almost modern & 1.2 & 91.4 & 53.7 & 62.2 & 13.4 & 5.6 \\
\hline Most modern & 0.0 & 94.0 & 56.5 & 61.9 & 10.7 & 6.2 \\
\hline $\mathrm{P}$ & .32 & .00 & .01 & .00 & .07 & .00 \\
\hline \multicolumn{7}{|l|}{ Disability } \\
\hline Yes & 2.9 & 71.4 & 38.0 & 48.0 & 20.0 & 5.3 \\
\hline No & 2.0 & 80.9 & 54.5 & 45.1 & 7.2 & 4.8 \\
\hline $\mathrm{P}$ & .71 & .10 & .02 & .68 & .00 & .08 \\
\hline
\end{tabular}

${ }^{a}$ Living with individuals other than children, children-in-law, spouse, parents, or grandchildren. 
holds are better able to pool resources and obtain better-quality housing. Although we might hypothesize that having a disability indicates a need for support and hence a greater tendency to live with others, we find no clear pattern in this regard. In fact, elderly Cambodians with a disability are less likely to be living with children than those without a disability, although the disabled elderly are more likely to be living in complex arrangements. Again, these ambiguous findings may be due to the cross-sectional nature of the data, which does not allow us to determine whether an older adult has recently moved in with another person after the onset of a health problem; or they may be due to the narrow definition of disability that excludes many of the typical functional limitations that generate a need for support in conducting daily activities.

\section{SEX AND Marital Status of a CORESiding ChILd}

Table 6 displays the percent of the total elderly population living with children according to sex and marital status. Also presented are the results from recent studies of Thailand and Vietnam. Similar to the case of Thailand, older Cambodians live with daughters more often than sons (about 56 percent versus about 44 percent). Looking at sex and marital status, older Cambodians are most likely to be living with never-married daughters (about 29 percent). The next most likely child to be living with an older adult is a never-married son, with the proportion (about 26 percent) only slightly lower. In contrast, the elderly in Thailand are most likely to be living with married daughters, while the Vietnamese elderly, particularly those in the north, are most likely to coreside with married sons. Another noteworthy living arrangement in Cambodia is that more than one in ten older adults coresides with a widowed daughter.

Male-to-female ratios are presented at the bottom of Table 6 . The overall son-todaughter ratio in Cambodia is very similar to that of Thailand (.78 versus .74), while Vietnamese ratios are greater than one, indicating a predominance of son coresidence. The congruence between Thai and Cambodian ratios may reflect the aforementioned similarity in their bilateral value systems. There are, however, some differences between the two countries with respect to the sex and marital status of coresident children. The ratio of married sons to married daughters is nearly 1.0 in Cambodia, suggesting little difference in the sex of a coresident married child, compared to a female-predomi- 
Table 6 Living arrangements of the elderly, by sex and marital status of coresident children, and sex ratio of such living arrangements: Cambodia and neighboring regions

\begin{tabular}{lcccr}
\hline & Cambodia & Thailand $^{\mathrm{a}}$ & $\begin{array}{r}\text { Southern } \\
\text { Vietnam }^{\mathrm{b}}\end{array}$ & $\begin{array}{r}\text { Northern } \\
\text { Vietnam }^{\mathrm{b}}\end{array}$ \\
\hline Percent living with & & & & \\
$\quad$ Any child & 80.5 & 70.9 & 85.9 & 75.1 \\
Son & 43.7 & 36.3 & 65.1 & 62.1 \\
Daughter & 55.7 & 49.3 & 48.3 & 24.5 \\
Married son & 18.3 & 19.6 & 46.1 & 50.5 \\
Married daughter & 19.7 & 33.8 & 26.4 & 6.2 \\
Never-married son & 25.7 & 20.5 & 34.5 & 17.4 \\
Never-married daughter & 29.3 & 20.0 & 32.3 & 19.3 \\
Widowed son & 1.1 & na & na & na \\
Widowed daughter & 11.0 & na & na & na \\
Ratio of: & & & & \\
Any son / any daughter & 0.78 & 0.74 & 1.35 & 2.53 \\
Married son / married daughter & 0.93 & 0.58 & 1.75 & 8.15 \\
$\quad$ Never-married son / never-married & 0.87 & 1.02 & 1.07 & 0.90 \\
daughter & .10 & na & na & na \\
$\quad$ Widowed son / widowed daughter & .10 & & & \\
\hline
\end{tabular}

a From Knodel and Chayovan (1997: Table 3)

b From Anh, Caong, Goodkind, and Knodel (1997: Table 5)

nant ratio of .58 in Thailand. But the situation with respect to widowed children clouds the issue in Cambodia and makes direct comparisons difficult. The elderly in Cambodia are about ten times more likely to be living with widowed daughters than with widowed sons. Some of those who live with widowed daughters might otherwise be living with married daughters, were it not for unusually high number of widowed women in Cambodia. Ratios of never-married sons to never-married daughters range from .87 to 1.07 across the four samples but are lowest in Cambodia. Never-married children are usually younger than married children and are not yet at the life-course stage where they move away from their parents. For this reason, the sex of a coresident unmarried child is often not a matter of choice and in most societies these ratios tend to be close to one.

The above data are informative, but they cannot indicate individual preferences for living arrangements. These data indicate proportions living with a particular child 
without assessing where older adults would be living given the particular sex composition of available children. For instance, if an older adult had three never-married daughters but no other children, they would have no choice. The difficulty in interpreting proportions is exacerbated in Cambodia owing to the excess mortality of males, which resulted in an excess availability of never-married and widowed females aged 18 to 59. The predominance of older adults living with daughters may be a consequence of this availability.

Although we lack the data to test for gender preference directly, we can provide an indirect test by introducing a procedure to adjust ratios for an unbalanced sex and marital status distribution. Here we consider only older adults who live with adult children aged 18 to 59 and the sex and marital status of those children. Focusing on those aged 18 and older allows us to examine the adult offspring who are most likely to serve as caretakers and also eliminates some of the randomness in the distribution of younger children who have not yet left home. Hence, it provides a better sense of elderly parents' gender preference even for their never-married children. The procedure juxtaposes the ratio expected a) if children of older adults were distributed according to their availability and b) if each older adult lived with only one child with the observed ratio. Expected ratios provide a measure of the availability of children of a given sex and marital status. We assume that the proportion of married, never-married, and widowed men or women aged 18 to 59 in the population is a measure of availability. Our formula for the adjusted ratio is:

$$
\theta_{\mathrm{i}}=\left(\mathrm{p}_{\mathrm{i}} / \mathrm{p}_{\mathrm{o}}\right) /\left(\pi_{\mathrm{i}} / \pi_{0}\right)
$$

where $\theta_{i}$ is the adjusted ratio for living with a particular child, $p_{i}$ is the proportion of older adults who live with such a child, and $p_{o}$ is the proportion who live with all other children of a given sex and marital status. Hence the numerator is the observed ratio. $\pi_{i}$ and $\pi_{o}$ are the proportions that actually exist within the population and hence represent the expected ratio. We ignore divorced and separated children since they account for a very small proportion of the total, that is, only 1.3 percent. $p_{i}+p_{o}$ will be greater than 1.0 since some older adults live with more than one child. $\pi_{i}$ and $\pi_{o}$ will be 1.0 minus the proportion divorced or separated. 
To provide an example, the proportion of the total Cambodian population that is female, never-married, and 18 to 59 years of age is 11.3 percent. The ratio of elderly parents living with never-married daughters to parents living with other children that would be expected if each older adult lived with only one child and if these children were randomly distributed among older adults is $.113 /(.987-.113)=.129$. The actual proportion of Cambodians who live with a never-married daughter among those who live with any child 18 to 59 is .316 , and the actual proportion living with others is .902 . The observed ratio is then $.316 / .902=.350$. Hence, the observed ratio is almost three times greater than the expected ratio. While a ratio of 1.0 would indicate that the number of elderly Cambodians living with this type of child is exactly the same as would be expected, our result provides evidence for a preference of living with never-married daughters.

We also adjust our ratios to examine all sons versus all daughters, married sons versus married daughters, never-married sons versus never-married daughters, and widowed sons versus widowed daughters. These further adjustments provide an indirect measure of gender preference. For instance, we noted that the proportion of never-married females is 11.3 percent. The proportion of never-married males is 10.8 percent. The ratio of $.108 / .113=.956$ would be expected in the absence of gender preference among elderly adults living with never-married children aged 18 to 59. The observed ratio of parents living with never-married sons to those living with never-married daughters aged 18 to 59 is .775 . Adjusting the ratio for availability, we get $.775 / .956=0.81$. This suggests that there may be some daughter preference in Cambodia when it comes to living with a never-married adult child between the ages of 18 and 59 .

Table 7 presents our findings. The top panel provides overall ratios, that is, the ratio of living with a child of a given gender and marital status versus living with all other children. The bottom panel examines adjusted gender ratios according to marital status. We examine these ratios for all of Cambodia as well as for each region in order to determine whether there is regional variation in the types of children with whom older adults live. Appendix Table A provides the percent distributions of the population by sex and marital status from which these ratios have been calculated.

Looking first at the results for all of Cambodia, older adults are more than twice as likely to be living with never-married sons and about 2.7 times more likely to be living with never-married daughters than would be expected. Conversely, in relation to 
Table 7 Adjusted sex and marital status ratios for children aged 18 to 59 coresiding with elderly parents by region

\begin{tabular}{lccccccc}
\hline & $\begin{array}{c}\text { All } \\
\text { Cambodia }\end{array}$ & Plains & $\begin{array}{c}\text { Tonle } \\
\text { Sap }\end{array}$ & Coastal & $\begin{array}{c}\text { Moun- } \\
\text { tain }\end{array}$ & $\begin{array}{c}\text { Phnom } \\
\text { Penh }\end{array}$ & P $^{\mathbf{b}}$ \\
\hline Married son(s) versus others & .48 & .44 & .50 & .53 & .57 & .58 & .48 \\
Married daughter(s) versus others & .49 & .50 & .44 & .31 & .48 & .72 & .00 \\
Never-married son(s) versus others & 2.04 & 2.06 & 2.27 & 3.83 & 1.56 & 1.38 & .49 \\
$\begin{array}{l}\text { Never-married daughter(s) } \\
\text { versus others }\end{array}$ & 2.71 & 2.73 & 3.06 & 3.01 & 2.40 & 1.91 & .35 \\
Widowed son(s) versus others & 1.71 & 1.55 & 1.48 & $0^{\text {a }}$ & $0^{\text {a }}$ & .73 & .70 \\
Widowed daugher(s) versus others & 1.60 & 1.63 & 1.33 & 1.83 & 2.93 & 1.61 & .55 \\
\hline All sons / all daughters & .87 & .82 & .92 & 1.19 & .87 & .89 & .07 \\
Married son(s) / married daughter(s) & .96 & .89 & 1.08 & 1.53 & 1.13 & .85 & .24 \\
Never-married son(s) / & & & & & & & \\
never-married daughter(s) & .81 & .83 & .78 & 1.22 & .70 & .76 & .01 \\
Widowed son(s) / widowed daughter(s) & 1.11 & .99 & 1.14 & $0^{\mathrm{a}}$ & $0^{\mathrm{a}}$ & .48 & .68 \\
\hline
\end{tabular}

a No widowed sons aged 18 to 59 living with older adults in this region.

b P-values derived from chi-square procedure that tests for significant differences across provinces.

availability, a small proportion of older adults live with married children: ratios for married sons and married daughters are each less than .50. The bottom panel shows an overall preference for daughters in coresidence (ratio of .87), even after adjusting for the excess number of women aged 18 to 59 in the population. This daughter preference, while not large, confirms expectations based on the Cambodian cultural and value system discussed earlier. Daughter preference appears to be stronger with respect to living with never-married rather than married children (ratios of .81 and .96 respectively). Elderly Cambodians are over 1.5 times more likely to be living with widowed children than would be expected given the availability of widowed adults aged 18 to 59. Although we saw earlier that those who live with widowed children are likely to be living with a daughter, our adjusted ratios do not indicate a gender preference either way. That is, the large number of elderly living with widowed daughters is a function of the vast difference in the proportion of widowed males versus females in the Cambodian population.

In every region, older Cambodians are more likely to be living with never-married sons and daughters and less likely to be living with married sons and daughters than expected based on availability. In four of five regions there is a slight daughter preference owing mainly to a preference for living with never-married daughters over never- 
married sons. The one exception is the Coastal region, where sons appear more likely to be living with older parents than would be expected. This exception found in Coastal Region is statistically significant in two respects. First, older adults are significantly less likely to be living with a married daughter than with any other older child; second, they are significantly more likely to be living with a never-married son than with a nevermarried daughter.

Our data do not inform us about the actual availability of sons and daughters for each older adult; this has only been implied from population totals. We also lack information on whether older adults tend to live with the youngest child or merely with one who is unmarried, although the predominance of living with never-married children seems to imply a preference for living with a younger child.

\section{SUMMARY AND IMPLICATIONS}

Cambodia has emerged from a long period of isolation with a population structure altered by decades of war. Now that Cambodia has become politically more stable, has reopened its borders, and has begun to collect data pertinent for social analysis, it is possible to investigate the conditions that exist for its elderly population and examine how its history has affected the elderly.

Our data indicated that Cambodia has a very low male-to-female sex ratio and a very high rate of female widowhood, particularly at ages when grown children begin to act as caregivers for aging parents. In these circumstances females head a disproportionate number of households. Our data (not provided in tabular form) show that about 25 percent of households have a female as the head, but this is true of 36 percent of households whose head is 50 to 59 years of age and 34 percent of households with an elderly person present. Several recent reports suggest that despite a bilateral system of coresident preference among older adults, women in Cambodia hold less authority and status than do men (Beaufils 2000; Kato 2000). As a result female-headed households are less likely to have higher-quality housing, to own land, or to have the funds necessary to pay for health care. Beaufils (2000) further suggests that the status of women in Cambodia has fallen as a result of the "surplus" of women. Even if daughters are typically expected to act as caregivers for older parents (Kato 2000), an additional burden might be shoul- 
dered by unmarried women, who on balance have fewer resources than do men. At the same time, women live longer and are more likely to suffer from nagging if not fatal health conditions such as those related to loss of strength and agility (Verburgge 1989); thus it is often older women who require care and assistance in conducting daily tasks. Given the excess of widowed women aged 40 to 60, the next generation of elderly Cambodians will be even more unbalanced than the current one. The future will likely see many elderly women who require care and support but do not have a spouse or children to act as caregivers. Hence, in both the short and long term, support structures of various kinds will quite possibly be inadequate.

In sum, the implications of the current study are mixed. On the one hand, patterns of living arrangements suggest very high rates of coresidence and similarities with neighboring states. This would imply that, like the elderly in Thailand and Vietnam, the needs of Cambodia's elderly will be met through intergenerational exchanges within the household. On the other hand, demographic change resulting from years of war and unrest has created a unique population structure with a female-dominated sex ratio and an abundance of widowed daughters-circumstances that are likely to have a negative effect on the resources available to older adults.

\section{IDEAS FOR FURTHER RESEARCH AND A NATIONAL Policy ON AGING}

Although social and demographic conditions in Cambodia went unstudied during the 1970s and 1980s, we know that this period involved excess mortality and mass out-migration. It is also clear that during periods of instability socioeconomic development was sluggish (Keirnan 1996; Chandler 2000). As a consequence, the health infrastructure suffered. Doctors in Cambodia today receive low incomes; health care workers are poorly trained and health care facilities are in disrepair; and pharmaceuticals that are used have often expired and their use is not properly monitored (Heng and Key 1995; Kato 2000). Widespread poverty means that many people cannot afford to pay for health expenses. AIDS has become a major problem, with rates of HIV infection being proportionately higher in Cambodia than anywhere else in Asia (Morisky and Coan 1998; Ryan et al. 1998). There is a distinct possibility that the AIDS virus will continue 
to spread quickly throughout the country, creating a multitude of health and social problems for all segments of the population.

These circumstances are particularly inauspicious for the elderly of Cambodia, who have experienced harsh conditions during the last several decades and now must deal with potential problems related to old age. Today, there are few nationally funded services designed to assist older adults (Kato 2000), but opportunities do exist. The Ministry of Social Affairs, Labour, and Veterans' Affairs is debating the implementation of a national policy on aging, although the Ministry's resources are inadequate for the task (Phillips 2000). Future research that examines the socio-demographic circumstances and particular social needs of Cambodia's elderly can inform such policy and assist in making it responsive to their needs.

Research needs to be conducted to understand the effects that the war and isolation have had on the older population. These effects are likely to be economic, demographic, physical, and emotional. It is possible that the violence, the loss of family members, and the harsh living conditions have led to emotional privations that require particular attention. Similarly, given the gender distribution that is a consequence of the violent past, research that examines gender differences in the aging experience, as well as differences in the way in which male and female adult children support aging parents, would be useful.

Despite some recent endeavors to collect socioeconomic data in Cambodia, including the efforts of HelpAge International (Kato 2000), we still know very little about the health, health behaviors, and health care utilization of the elderly population, how these compare with other parts of Asia, and what related services are needed. In some ways, questions of morbidity are more important than those of mortality. Maintaining health in old age means that the elderly can preserve some level of autonomy and of productive and satisfying activity, as a result of which they can maintain their selfesteem. Although we know that overall health conditions in Cambodia are poor, we do not know to what extent the burden of disease affects the elderly members of society and the overall effect of illness and physical limitations on their quality of life.

Finally, any national policy on aging needs to consider the demographic context in which older adults live. This involves understanding how the family cooperates to 
provide assistance, where assistance is coming from, and what potential sources of support exist outside the household. We need to examine the financial exchanges that take place between older adults and other family members and how health care costs are paid for. Moreover, it is essential to understand how older adults themselves contribute to the household, whether economically and otherwise. Given the AIDS epidemic currently affecting Cambodia, older adults may play a crucial role in providing health care for their infected children and child care for their grandchildren. The development of an aging policy needs to reflect traditional Cambodian values, which means taking into account reciprocal supporting roles between elders and members of their family and enhancing the family's ability to provide care. Given Cambodia's recent entry into a period of relative stability, the current environment quite possibly will be more conducive to such undertakings.

Appendix Table A Percent of adults aged 60 and older who live with children aged 18 to 59 , and percent of the population aged 18 to 59 , by sex and marital status

\begin{tabular}{|c|c|c|c|c|c|c|}
\hline & $\begin{array}{c}\text { All } \\
\text { Cambodia }\end{array}$ & Plains & $\begin{array}{l}\text { Tonle } \\
\text { Sap }\end{array}$ & Coastal & $\begin{array}{c}\text { Moun- } \\
\text { tain }\end{array}$ & $\begin{array}{c}\text { Phnom } \\
\text { Penh } \\
\end{array}$ \\
\hline \multicolumn{7}{|c|}{$\begin{array}{l}\text { Percent of older adults } \\
\text { living with children } 18 \text { to } 59 \\
\text { who live with... }\end{array}$} \\
\hline Any son & 49.5 & 45.5 & 50.5 & 57.7 & 49.1 & 54.7 \\
\hline Any daughter & 72.3 & 70.7 & 65.3 & 59.0 & 67.3 & 71.5 \\
\hline Married son(s) & 23.6 & 21.8 & 24.0 & 28.2 & 29.1 & 28.5 \\
\hline Married daughter(s) & 26.0 & 25.9 & 23.7 & 19.2 & 27.3 & 36.5 \\
\hline Never-married son(s) & 24.5 & 23.0 & 26.5 & 29.5 & 20.0 & 26.3 \\
\hline Never-married daughter(s) & 31.6 & 33.7 & 30.3 & 26.9 & 27.3 & 27.0 \\
\hline Widowed son(s) & 1.5 & 1.6 & 1.6 & 0.0 & 0.0 & 0.7 \\
\hline Widowed daughter(s) & 14.7 & 15.0 & 12.0 & 14.1 & 20.0 & 17.5 \\
\hline \multicolumn{7}{|l|}{$\begin{array}{l}\text { Percent of the population } \\
18 \text { to } 59 \text { who are... }\end{array}$} \\
\hline Male & 44.8 & 44.0 & 45.6 & 45.1 & 45.6 & 46.3 \\
\hline Female & 55.2 & 56.0 & 54.4 & 54.9 & 54.4 & 53.7 \\
\hline Married males & 33.0 & 32.9 & 33.1 & 36.5 & 34.2 & 30.8 \\
\hline Married females & 35.1 & 34.9 & 35.3 & 37.9 & 36.1 & 33.3 \\
\hline Never-married males & 10.8 & 10.1 & 11.1 & 7.9 & 10.9 & 14.6 \\
\hline Never-married females & 11.3 & 12.3 & 9.9 & 8.8 & 10.4 & 11.4 \\
\hline Widowed males & 0.8 & 0.8 & 0.9 & 0.6 & 0.2 & 0.7 \\
\hline Widowed females & 7.8 & 7.9 & 7.7 & 6.8 & 6.1 & 8.4 \\
\hline
\end{tabular}




\section{References}

Anh, Truong Si, Bui The Cuong, Daniel Goodkind, and John Knodel. 1997. "Living arrangements, patrilinearity and sources of support among elderly Vietnamese," Asia-Pacific Population Journal 12(4): 69-88.

Asis, Maruja Milagros B., Lita Domingo, John Knodel, and Kalyani Mehta. 1995. "Living arrangements in four Asian countries: A comparative perspective," Journal of Cross-Cultural Gerontology 10: 145-162.

Beaufils, Laure. 2000. Population Matters in Cambodia. Phnom Penh, Cambodia: United Nations Population Fund.

Blalock, Herbert M., Jr. 1979. Social Statistics. New York: McGraw-Hill.

Bongaarts, John and Zachary Zimmer. 2001. "Living arrangements of older adults in the developing world: An analysis of DHS household surveys," Policy Research Division Working Paper No. 148. New York: Population Council.

Casterline, John B., Lindy Williams, Albert Hermalin, M.C. Chang, Napaporn Chayovan, Paul Cheung, Lita Domingo, John Knodel, and Mary Beth Ofstedal. 1991. "Differences in living arrangements of the elderly in four Asian countries: The interplay of constraints and preferences," Comparative Study of the Elderly in Asia, Research Report No. 91-10. Ann Arbor: Population Studies Center, University of Michigan.

Chandler, David. 2000. A History of Cambodia. 3rd ed. Boulder, CO: Westview Press.

Colet, John and Joshua Eliot. 1997. Cambodia Handbook. Chicago: Footprints Handbooks.

DaVanzo, Julie and Angelique Chan. 1994. "Living arrangements of older Malaysians: Who coresides with their adult children?" Demography 31(1): 95-113.

Gordon, Linda W. 1990. "Southeast Asian refugees migration to the United States," in James T. Fawcett and B.V. Carino (eds.), Pacific Bridges: The New Immigration from Asia and the Pacific Islands. Staten Island, NY: Center for Migration Studies.

Heng, Mam Bun and P.J. Key. 1995. "Cambodian health in transition," British Medical Journal 311(August 12): 435-437. 
Hermalin, Albert I. 1995. "Aging in Asia: Setting the research foundation,” Asia-Pacific Population Research Report No. 4. Honolulu: East-West Center.

Hermalin, Albert I., Mary Beth Ofstedal, and Ming-Cheng Chang. 1996. "Types of supports for the aged and their providers in Taiwan," in Tamara K. Hareven (ed.), Aging and Generational Relations Over the Life Course: A Historical and CrossCultural Perspective. New York: Walter de Gruyter, pp. 400-437.

Heuveline, Patrick. 1998. “'Between one and three million': Towards the demographic reconstruction of a decade of Cambodian history (1970-79)," Population Studies 52: 49-65.

Huguet, Jerrold W. 1991. “The demographic situation in Cambodia," Asia-Pacific Population Journal 6(4): 79-91.

Huguet, Jerrold W., Aphichat Chamratrithirong, Nott Rama Rao, and San Sy Than. 2000. "Results of the 1998 population census in Cambodia," Asia-Pacific Population Journal 15(3): 3-22.

Kato, Elizabeth Uphoff. 2000. "Ageing in Cambodia: Tradition, change and challenges," in David R. Phillips (ed.), Ageing in the Asia-Pacific Region. New York: Routledge, pp. 360-374.

Katz, S., A.B. Ford, R.W. Moskowitz, B.A. Jackson, and M.W. Jaffee. 1963. "Studies of illness in the aged: The index of ADL, a standardized measure of biological and psychosocial function," Journal of the American Medical Association 185: 914919.

Keirnan, Ben. 1996. The Pol Pot Regime: Race, Power, and Genocide in Cambodia under the Khmer Rouge, 1975-1979. New Haven: Yale University Press.

Kim, I.K. and E.H. Choe. 1992. "Support exchange patterns of the elderly in the Republic of Korea," Asia-Pacific Population Journal 7(3): 89-104.

Knodel, John, Pattama Amornsirisomboon, and Jiraporn Khiewyoo. 1997. "Living arrangements, family support and the welfare of the elderly: Findings and implications of the 1994 Survey of Elderly in Thailand," Comparative Study of the Elderly in Asia, Research Report No. 97-43. Ann Arbor: Population Studies Center, University of Michigan. 
Knodel, John and Napaporn Chayovan. 1997. "Family support and living arrangements of Thai elderly," Asia-Pacific Population Journal 12(4): 51-68.

Knodel, John, Napaporn Chayovan, and Siriwan Siriboon. 1992. "The familial support system of Thai elderly: An overview," Asia-Pacific Population Journal 7(3): 105126.

Knodel, John and Nibhon Debavalya. 1997. "Living arrangements and support among the elderly in South-East Asia: An introduction," Asia-Pacific Population Journal 12(4): 3-13.

Knodel, John, Chanpen Saengtienchai, and Berit Ingersoll-Dayton. 1999. "Studying the living arrangements of the elderly: Lessons from a quasi-qualitative case study approach in Thailand," Journal of Cross-Cultural Gerontology 14(3): 197-220.

Mason, Karen Oppenheim. 1992. "Family change and support of the elderly in Asia: What do we know?” Asia-Pacific Population Journal 7(3): 13-32.

Meng-Try, EA. 1981. "Kampuchea: A country adrift," Population and Development Review 7(2): 209-228.

Ministry of Planning. 1999a. Cambodian Human Development Report. Phnom Penh, Cambodia: Ministry of Planning.

Ministry of Planning. 1999b. 1998 Census Priority Tables. Phnom Penh, Cambodia: National Institute of Statistics and Ministry of Planning.

Morisky, Donald E.M. and Dara L. Coan. 1998. "Asia: The new epidemic zone for HIV/ AIDS,” Journal of Health Communication 3(3): 185-191.

Nagi, Saad Z. 1976. "An epidemiology of disability among adults in the United States," Milbank Memorial Fund Quarterly 54: 439-468.

National Institute of Statistics. 1997a. Cambodia Socio-Economic Survey 1997: Technical Report on Survey Design and Implementation. Phnom Penh, Cambodia: NIS.

National Institute of Statistics. 1997b. Socio-Economic Survey of Cambodia 1996: Volume II Summary Results. Phnom Penh, Cambodia: NIS.

National Institute of Statistics. 2000. General Population Census of Cambodia 1998. 
Phnom Penh, Cambodia: National Institute of Statistics and United Nations Population Fund.

Natividad, Josefina N. and Grace T. Cruz. 1997. "Patterns in living arrangements and familial support for the elderly in the Philippines," Asia-Pacific Population Journal 12(4): 17-34.

Ofstedal, Mary Beth, John Knodel, and Napaporn Chayovan. 1997. "Intergenerational support and gender: A comparison of four Asian countries," Journal of Southeast Asian Studies 27(2).

Phillips, David R. 2000. "Ageing in the Asia-Pacific region: Issues, policies and contexts," in David R. Phillips (ed.), Ageing in the Asia-Pacific Region. New York: Routledge, pp. 1-34.

Robinson, W.C. 1989. "Population trends and policies in Laos (Lao People's Democratic Republic) and Cambodia (Democratic Kampuchea)," in International Population Conference, Volume 1, New Delhi, 1989: International Union for the Scientific Study of Population. Liège: IUSSP, pp. 143-153.

Ryan, Caroline A., Ouk Vong Vathiny, Pamina M Gorbach, Hor Bun Leng, A. BerliozArthaud, W.L. Whittington, and King K. Holmes. 1998. "Explosive spread of HIV-1 and sexually transmitted disease in Cambodia," Lancet 351(9110): 11751176.

Thornton, Arland, Ming-Cheng Chang, and Te-Hsiung Sun. 1984. "Social and economic change, intergenerational relationships, and family formation in Taiwan," Demography 21(4): 475-499.

United Nations. 1999. World Population Prospects: The 1998 Revision. New York.

Verbrugge, Lois M. 1989. "The twains meet : Empirical explanations for sex differences in health and mortality," Journal of Health and Social Behavior 30: 282304.

Vickery, Michael. 1986. Kampuchea: Politics, Economics and Society. London: Frances Pinter.

World Fact Book 1998. Washington, DC: Brassey's. 


\title{
POLICY RESEARCH DIVISION WORKING PAPERS
}

\author{
Recent Back Issues
}

133 Mary Arends-Kuenning and Sajeda Amin, "The effects of schooling incentive programs on household resource allocation in Bangladesh."

134 John Bongaarts and Charles F. Westoff, "The potential role of contraception in reducing abortion."

135 John B. Casterline and Steven W. Sinding, "Unmet need for family planning in developing countries and implications for population policy."

*136 Carol E. Kaufman, Thea de Wet, and Jonathan Stadler, "Adolescent pregnancy and parenthood in South Africa."

*137 Valerie L. Durrant and Zeba A. Sathar, "Greater investments in children through women's empowerment: A key to demographic change in Pakistan?"

138 Sajeda Amin, Alaka Malwade Basu, and Rob Stephenson, "Spatial variation in contraceptive use in Bangladesh: Looking beyond the borders."
139 Geoffrey McNicoll, "Managing population-environment systems: Problems of institutional design."

140 Barbara S. Mensch, Barbara L. Ibrahim, Susan M. Lee, and Omaima ElGibaly, "Socialization to gender roles and marriage among Egyptian adolescents."

141 John Bongaarts and Elof Johansson, "Future trends in contraception in the developing world: Prevalence and method mix."

142 Alaka Malwade Basu and Sajeda Amin, "Some preconditions for fertility decline in Bengal: History, language identity, and an openness to innovations."

143 Zeba Sathar, Cynthia B. Lloyd, Cem Mete, and Minhaj ul Haque, "Schooling opportunities for girls as a stimulus for fertility change in rural $\mathrm{Pa}-$ kistan."

* No longer available 
144 John Bongaarts, "Household size and composition in the developing world."

145 John B. Casterline, Zeba A. Sathar, and Minhaj ul Haque, "Obstacles to contraceptive use in Pakistan: A study in Punjab."

146 Zachary Zimmer, Albert I. Hermalin, and Hui-Sheng Lin, "Whose education counts? The impact of grown children's education on the physical functioning of their parents in Taiwan."

147 Philomena Nyarko, Brian Pence, and Cornelius Debpuur, "Immunization status and child survival in rural Ghana."

148 John Bongaarts and Zachary Zimmer, "Living arrangements of older adults in the developing world: An analysis of DHS household surveys."

149 Markos Ezra, "Ecological degradation, rural poverty, and migration in Ethiopia: A contextual analysis."
150 Cynthia B. Lloyd, Sahar El Tawila, Wesley H. Clark, and Barbara S. Mensch, "Determinants of educational attainment among adolescents in Egypt: Does school quality make a difference?"

151 Barbara S. Mensch, Paul C. Hewett, and Annabel Erulkar, " The reporting of sensitive behavior among adolescents: A methodological experiment in Kenya."

152 John Bongaarts, "The end of the fertility transition in the developed world."

153 Mark R. Montgomery, Gebre-Egziabher Kiros, Dominic Agyeman, John B. Casterline, Peter Aglobitse, and Paul Hewett, "Social networks and contraceptive dynamics in southern Ghana."

154 Paul C. Hewett and Mark R. Montgomery, "Poverty and public services in developing-country cities."

2002

155 Zachary Zimmer, Linda G. Martin, and Ming-Cheng Chang, "Changes in functional limitations and survival among the elderly in Taiwan: 1993, 1996, and 1999."
156 John Bongaarts and Griffith Feeney, "How long do we live?"

157 Zachary Zimmer and Sovan Kiry Kim, "Living arrangements and socio-demographic conditions of older adults in Cambodia." 